\title{
Prevalence, Incidence, and Characteristics of Tuberculosis Among Known Diabetes Patients - A Prospective Cohort Study in 10 Sites, 2013-2015
}

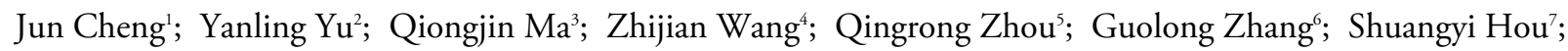

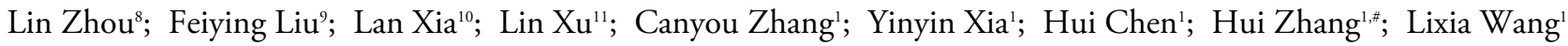

\section{Summary \\ What is already known about this topic? \\ The association of diabetes mellitus (DM) with both increased risk of tuberculosis (TB) and unfavorable treatment outcomes has been identified by many studies (1). However, epidemic data for TB cases in DM patients is absent in China. \\ What is added by this report? \\ This current population-based prospective cohort study, conducted in ten counties located in eastern, central, and western China during 2013-2015, revealed a high prevalence and incidence of TB in known DM patients. Most TB cases were captured by active case-finding and a much higher presence of being asymptomatic among TB/DM patients was obtained. \\ What are the implications for public health practice? \\ Active case-finding should be carried out in DM patients and populations at high risk for developing TB. A TB symptom screening-based case-finding strategy is not enough; chest radiography check should be done once a year for these patients.}

The evidence for positive association of diabetes mellitus (DM) and tuberculosis (TB) has been found by many studies regardless of study design and population (1), and the risk for developing $\mathrm{TB}$ increased among DM patients. China has a heavy burden for both DM and TB. During 2013-2015, there was an estimated number of TB cases between 0.918 million and 0.980 million, and meanwhile, China witnessed a high prevalence of DM in the past decade (2). And, there will also be an explosion in DM cases in China, with an estimated DM population of 20.8 million in 2000 and a projected number of 42.3 million by 2030 (3). Passive case finding was applied in DM patients in National Tuberculosis Control Program in China (China NTP), which likely resulted in underdiagnosed TB cases in DM patients, and the strong association between DM and TB and the high burden for these two diseases make a voice for more effective TB case finding in China. A population-based multicenter prospective cohort study for TB incidence in 10 study sites from 10 provincial-level administrative divisions in China was conducted during 2013-2015. This article used existing data to describe TB prevalence rate and incidence rate among patients with DM. The prevalence rates of bacteriologically-confirmed $\mathrm{TB}$ and active $\mathrm{TB}$ were 291.3/100,000 and 543.7/100,000, respectively; the incidence rates were 47.0/100,000 and 250.6/10,000, respectively. There was significant difference for both $\mathrm{TB}$ prevalence and $\mathrm{TB}$ incidence between genders, with or without previously treated $\mathrm{TB}$ and body mass index (BMI) level differentiation. About $81.8 \%$ of active $\mathrm{TB}$ was found by active screening. For TB patients identified by active screening, they had few TB symptoms present (less than 15\%) and more mild illness than those identified by passive case finding, signifying the necessity of active case-finding for highrisk populations.

The detailed information on site selection, the procedure and measurements used in the prevalence survey, and follow-up in the elderly have been described fully in other papers (4-5). And this study utilized data on DM patients obtained from the same study and aimed to understand the TB epidemic in DM patients.

Eligible DM patients were identified by using a twostage procedure. First, information was collected for all DM patients registered and managed in local National Project of Basic Public Health Service Project (NPHSP), which was launched by the Chinese Ministry of Health in 2011. Second, we made a doorto-door investigation to identify DM patients missed by the NPHSP.

All DM patients went through two phases: baseline 
and follow-up. In the baseline phase, each patient participated in a TB prevalence survey, which consisted of a questionnaire interview, chest X-ray examination (CXR); afterwards, a TB check was conducted for those with TB symptoms or abnormal CXR. In the follow-up phase, each DM patient without $\mathrm{TB}$ was followed up for two years to track TB incident cases by using both passive case-finding and yearly CXR.

A total of 6,025 DM patients were recruited for the study, with 5,180 managed and 845 missed by the local NPHSP project. Among all DM patients, 875 $(11.8 \%)$ refused to receive screening and 5,150 finished all required diagnostic procedure. Overall, 28 $\mathrm{TB}$ cases were identified in the prevalence survey, leaving 5,122 DM patients in the incidence cohort. At the end of two-year follow-up period, 3,033 DM patients remained in the cohort for data analysis.

Of the 5,150 DM patients, 28 active pulmonary TB patients were found, 4 of them were previously known patients with TB and 24 were newly diagnosed with TB. The overall prevalence rates of bacteriologicallyconfirmed $\mathrm{TB}$ and clinically-diagnosed $\mathrm{TB}$ were 291.3/100,000 and 543.7/100,000, respectively. Table 1 shows $\mathrm{TB}$ prevalence for each group with different characteristics.

Of the 5,122 DM patients without TB, 6,383.6 person-years and 16 incident active pulmonary $\mathrm{TB}$ patients were obtained. The overall incidence rates of bacteriologically-confirmed $\mathrm{TB}$ and clinicallydiagnosed TB in these person-years were 47.0/100,000 person-year and 250.6/100,000 person-year, respectively. Table 2 shows $\mathrm{TB}$ incidence for each group with different characteristics.

For 44 active TB patients with DM, including 28 found in baseline survey and 14 identified during the follow-up period, 8 cases $(18.2 \%)$ were found by passive case-finding, and 36 cases (81.8\%) were captured by active screening. The prevalences of TB symptoms were $50.0 \%$ and $70.4 \%$ in all bacteriologically-confirmed and clinically-diagnosed $\mathrm{TB}$, respectively, and decreased to $18.2 \%$ and $13.9 \%$, respectively, among $\mathrm{TB}$ cases identified by active screening. Significant differences of TB symptom prevalence existed between TB patients found by the two methods. In addition, most active TB patients had 1-2 lung fields lesion, and about 38\% involved lower lung fields and both left and right lungs. Overall, 18\% of TB patients presented cavitation in their chest imaging. These percentages increased in bacteriologically-confirmed TB patients (Table 3).

\section{DISCUSSION}

Our study is the first population-based and prospective cohort study in known DM patients, obtaining both prevalence and incidence rates of TB and describing TB symptom presence and characteristics of chest imaging change for DM/TB patients. The study also observed a higher prevalence of bacteriologically-confirmed TB in known DM patients than that for the general population based on data obtained from the Fifth National Tuberculosis Prevalence Survey. Compared with a retrospective cohort study conducted in Shanghai (6), our study obtained a much higher TB incidence rate in larger areas. Our active TB incidence was also higher than that obtained in a cohort study conducted in the Republic of Korea $(7)$ and lower than that obtained in Indonesia (8). The reason underlying the difference is because there is a huge difference in TB epidemic in these regions/countries.

The analyses for both $\mathrm{TB}$ prevalence and $\mathrm{TB}$ incidence in several subgroups showed significant differences. Male DM patients with lower BMI had higher $\mathrm{TB}$ prevalence and incidence rates; these findings were like those identified in the general population and could be found in retrospective cohort study conducted in Shanghai (G). A history of previous TB was identified as a high-risk factor for developing TB by many studies (9). For persons with multiple risk factors, their risk for developing TB was much higher. Our analysis also indicated high TB prevalence and TB incidence for DM patients with previously treated TB.

Some pilot projects for TB screening among DM patients have been carried out in DM clinics and community health settings in the past few years (10). These pilots were based on TB symptoms, and five symptoms, including cough for longer than 2 weeks; night sweats for 4 weeks or longer, fever for 4 weeks or longer, weight loss over the previous 4 weeks, and any suspicion of active TB to account for extrapulmonary $\mathrm{TB}$, were used. All these pilots reported that it is feasible to carry out TB screening on DM patients, and a high detection rate for $\mathrm{TB}$ was obtained in clinic. The high yield obtained in our study also identified the feasibility of conducting active case-finding in community settings.

Passive case-finding is still the main strategy for TB case-finding in the China NTP, covering DM patients. $\mathrm{TB}$ could be diagnosed for DM patients visiting hospital actively due to the presence of TB symptoms. 
TABLE 1. Prevalence of tuberculosis for diabetes mellitus patients in 10 study sites in 2013.

\begin{tabular}{|c|c|c|c|c|c|c|c|}
\hline \multirow[b]{2}{*}{ Variables } & \multirow[b]{2}{*}{ No. } & \multicolumn{3}{|c|}{ Bacteriologically confirmed TB } & \multicolumn{3}{|c|}{ Active TB } \\
\hline & & $\begin{array}{l}\text { No. of TB } \\
\text { cases }\end{array}$ & $\begin{array}{c}\text { Prevalence } \\
(1 / 100,000)(95 \% \mathrm{Cl})\end{array}$ & $\boldsymbol{P}$ & $\begin{array}{l}\text { No. of TB } \\
\text { cases }\end{array}$ & $\begin{array}{c}\text { Prevalence } \\
(1 / 100,000)(95 \% \mathrm{Cl})\end{array}$ & $\boldsymbol{P}$ \\
\hline Total & 5,150 & 15 & $291.3(143.9-438.7)$ & & 28 & $543.7(342.3-745.1)$ & \\
\hline Gender & & & & 0.281 & & & 0.002 \\
\hline Female & 2,927 & 3 & $102.5(21.1-299.6)$ & & 8 & $273.3(117.9-538.4)$ & \\
\hline Male & 2,223 & 12 & $539.8(234.4-845.2)$ & & 20 & $899.7(505.4-1294)$ & \\
\hline Age group, years & & & & 0.547 & & & 0.060 \\
\hline$<55$ & 1,037 & 2 & $192.9(23.3-696.2)$ & & 2 & $192.9(23.3-696.2)$ & \\
\hline $55-$ & 1,707 & 5 & $292.9(94.9-683.7)$ & & 10 & $585.8(222.7-948.9)$ & \\
\hline $65-$ & 1,585 & 3 & $189.3(39.1-553.3)$ & & 7 & $441.6(177.3-909.8)$ & \\
\hline$\geq 75$ & 817 & 5 & $612.0(198.3-1,428.4)$ & & 9 & $1,101.6(504.3-2,090.6)$ & \\
\hline Nationality & & & & 0.916 & & & 0.814 \\
\hline Han & 4,834 & 14 & 289.6(137.9-441.3) & & 26 & $537.9(331.1-744.6)$ & \\
\hline Others & 313 & 1 & $319.5(8.1-1,779.6)$ & & 2 & $639(77.3-2,306.7)$ & \\
\hline Education & & & & 0.798 & & & 0.656 \\
\hline Senior middle school and above & 1,147 & 3 & $261.6(54.0-764.6)$ & & 5 & $435.9(141.2-1,017.4)$ & \\
\hline Junior middle school and less & 2,969 & 9 & $303.1(138.8-575.3)$ & & 16 & $538.9(274.8-803.0)$ & \\
\hline Illiteracy & 959 & 3 & $312.8(64.5-914.5)$ & & 7 & $729.9(293.0-1,503.6)$ & \\
\hline With or without spouse & & & & 0.512 & & & 0.166 \\
\hline Yes & 4,350 & 12 & $275.9(119.8-431.9)$ & & 21 & $482.8(276.3-689.2)$ & \\
\hline No & 800 & 3 & $375.0(77.4-1,096.3)$ & & 7 & $875.0(351.3-1,802.5)$ & \\
\hline Residence & & & & & & & 0.044 \\
\hline Locally & 4,502 & 15 & $333.2(164.6-501.8)$ & & 25 & $555.3(337.6-773.0)$ & \\
\hline Others & 648 & 0 & $0.0(0.0-569.4)$ & & 0 & $0.0(0.0-569.4)$ & \\
\hline Yearly income per person (CNY) & & & & 0.882 & & & 0.001 \\
\hline 10,000 and above & 3,173 & 4 & $126.1(34.4-322.7)$ & & 8 & $252.1(108.7-496.7)$ & \\
\hline $2,300-$ & 1,508 & 9 & $596.8(273.2-1,132.6)$ & & 17 & $1,127.3(591.4-1,663.2)$ & \\
\hline$<2,300$ & 352 & 2 & $568.2(68.8-2,051.1)$ & & 3 & $852.3(175.9-2,491.5)$ & \\
\hline Years for diabetes & & & & 0.201 & & & 0.751 \\
\hline$<10$ & 2,368 & 8 & $337.8(145.7-665.5)$ & & 15 & $633.4(312.9-954.0)$ & \\
\hline$\geq 10$ & 813 & 5 & $615.0(199.3-1,435.4)$ & & 6 & $738.0(270.6-1,606.4)$ & \\
\hline Previously treated TB & & & & 0.885 & & & $<0.001$ \\
\hline No & 5,019 & 10 & $199.2(75.8-322.7)$ & & 19 & $378.6(208.3-548.8)$ & \\
\hline Yes & 131 & 5 & $3,816.8(1,236.6-8,908.4)$ & & 9 & $6,870.2(3,145-13,038.2)$ & \\
\hline Chronic bronchitis & & & & 0.274 & & & 0.838 \\
\hline No & 4,913 & 15 & $305.3(150.8-459.8)$ & & 27 & $549.6(342.3-756.9)$ & \\
\hline Yes & 224 & 0 & $0.0(0.0-1,647.3)$ & & 1 & $446.4(11.3-2,486.6)$ & \\
\hline Pneumoconiosis & & & & $-*$ & & & 0.824 \\
\hline No & 5,136 & 15 & 292.1(144.3-439.9) & & 28 & $545.2(343.2-747.1)$ & \\
\hline Yes & 9 & 0 & $0.0(0.0-41,000.0)$ & & 0 & $0.0(0.0-41,000.0)$ & \\
\hline Self-reported cigarette smoking & & & & 0.353 & & & 0.444 \\
\hline Never smoking & 4,114 & 12 & $291.7(126.6-456.7)$ & & 24 & $583.4(350-816.8)$ & \\
\hline Ever or current smoking & 1,033 & 3 & 290.4(59.9-849.0) & & 4 & $387.2(105.5-991.3)$ & \\
\hline Self-reported drinking & & & & 0.022 & & & 0.947 \\
\hline Never drinking & 4,240 & 10 & $235.8(89.7-382.0)$ & & 23 & $542.5(320.8-764.1)$ & \\
\hline Ever or current drinking & 892 & 5 & $560.5(181.6-1,308.3)$ & & 5 & $560.5(181.6-1,308.3)$ & \\
\hline BMI level & & & & 0.275 & & & $<0.001$ \\
\hline$<18.5$ & 244 & 2 & $819.7(99.2-2,959.0)$ & & 6 & $2,459(901.6-5,352.5)$ & \\
\hline $18.5-$ & 2,568 & 12 & $467.3(202.9-731.7)$ & & 18 & $700.9(377.1-1,024.7)$ & \\
\hline $24-$ & 1,785 & 1 & $56.0(1.4-312.0)$ & & 3 & $168.1(34.7-491.3)$ & \\
\hline $28-$ & 550 & 0 & $0.0(0.0-670.9)$ & & 1 & $181.8(4.6-1,012.7)$ & \\
\hline
\end{tabular}

Note: 10 study sites: located in Zhejiang, Jiangsu, Guangdong, Shanghai, Heilongjiang, Henan, Hubei, Sichuan, Guangxi, and Yunnan. Not all total numbers for subgroups were 5,150 because of missing data.

Abbreviations: $\mathrm{DM}=$ diabetes mellitus; TB=tuberculosis; $\mathrm{BMI}=$ body mass index.

* Unavailable result because of no enough TB cases in this subgroup. 
TABLE 2. Incidence rates of tuberculosis in diabetes mellitus patient cohort in 10 study sites, 2013-2015.

\begin{tabular}{|c|c|c|c|c|c|c|c|}
\hline \multirow[b]{2}{*}{ Variables } & \multirow[b]{2}{*}{$\begin{array}{l}\text { Person- } \\
\text { year }\end{array}$} & \multicolumn{3}{|c|}{ Bacteriologically confirmed TB } & \multicolumn{3}{|c|}{ Active TB } \\
\hline & & $\begin{array}{c}\text { No. of } \\
\text { incident TB } \\
\text { cases }\end{array}$ & $\begin{array}{l}\text { Incidence }(1 / 100,000 \\
\text { person-year) }(95 \% \mathrm{Cl})\end{array}$ & $P$ & $\begin{array}{c}\text { No. of } \\
\text { incident TB } \\
\text { cases }\end{array}$ & $\begin{array}{l}\text { Incidence }(1 / 100,000 \\
\text { person-year) }(95 \% \mathrm{Cl})\end{array}$ & $P$ \\
\hline Total & $6,383.6$ & 3 & $47.0(9.7-137.4)$ & & 16 & $250.6(127.8-373.5)$ & \\
\hline Gender & & & & 0.340 & & & 0.006 \\
\hline Female & $3,800.8$ & 0 & $0.0(0.0-97.1)$ & & 4 & $105.2(28.7-269.4)$ & \\
\hline Male & $2,582.8$ & 3 & $116.2(24.0-339.6)$ & & 12 & $464.6(201.7-727.5)$ & \\
\hline Age group, years & & & & 0.103 & & & 0.408 \\
\hline$<55$ & $1,283.1$ & 2 & $155.9(18.9-562.7)$ & & 3 & $233.8(48.2-683.5)$ & \\
\hline $55-$ & $2,129.5$ & 1 & $47.0(1.2-261.6)$ & & 4 & $187.8(51.2-480.9)$ & \\
\hline $65-$ & $2,008.7$ & 0 & $0.0(0.0-183.7)$ & & 5 & $248.9(80.7-581.0)$ & \\
\hline$\geq 75$ & 960.3 & 0 & $0.0(0.0-384.3)$ & & 4 & $416.6(113.5-1,066.4)$ & \\
\hline Nationality & & & & 0.800 & & & $<0.001$ \\
\hline Han & 5994.6 & 3 & $50.0(10.3-146.3)$ & & 12 & $200.2(86.9-313.4)$ & \\
\hline Others & 387.5 & 0 & $0.0(0.0-952.3)$ & & 4 & $1,032.3(281.3-2,642.8)$ & \\
\hline Education & & & & 0.064 & & & 0.340 \\
\hline High school and above & $1,154.8$ & 2 & $173.2(21.0-625.2)$ & & 2 & $173.2(21.0-625.2)$ & \\
\hline $\begin{array}{l}\text { Secondary school and } \\
\text { less }\end{array}$ & $3,811.0$ & 1 & $26.2(0.7-146.2)$ & & 13 & $341.1(155.7-526.6)$ & \\
\hline Illiteracy & $1,336.5$ & 0 & $0.0(0.0-276.1)$ & & 1 & $74.8(1.9-416.8)$ & \\
\hline With or without spouse & & & & 0.638 & & & 0.272 \\
\hline Yes & $5,380.2$ & 3 & $55.8(11.5-163.0)$ & & 16 & $297.4(151.7-443.1)$ & \\
\hline No & $1,003.4$ & 0 & $0.0(0.0-367.8)$ & & 0 & $0.0(0.0-367.8)$ & \\
\hline Residence & & & & 0.828 & & & 0.615 \\
\hline Locally & $5,925.2$ & 3 & $50.6(10.4-148.0)$ & & 16 & $270.0(137.7-402.4)$ & \\
\hline Others & 458.4 & 0 & $0.0(0.0-805.0)$ & & 0 & $0.0(0.0-805.0)$ & \\
\hline $\begin{array}{l}\text { Yearly income per person } \\
\text { (CNY) }\end{array}$ & & & & 0.382 & & & 0.198 \\
\hline 10,000 and above & $3,586.5$ & 3 & 83.6(17.3-244.5) & & 6 & $167.3(61.3-364.1)$ & \\
\hline 2,300 & $2,139.1$ & 0 & $0.0(0.0-172.5)$ & & 8 & $374.0(161.3-736.8)$ & \\
\hline$<2,300$ & 502.1 & 0 & $0.0(0.0-734.9)$ & & 2 & $398.3(48.2-1,438.0)$ & \\
\hline Years for diabetes & & & & 0.788 & & & 0.329 \\
\hline$<10$ & $3,433.2$ & 2 & $58.3(7.0-210.3)$ & & 8 & $233.0(100.5-459.0)$ & \\
\hline$\geq 10$ & $1,191.0$ & 1 & $84.0(2.1-467.7)$ & & 5 & $419.8(136.0-979.8)$ & \\
\hline unknown & $1,759.3$ & 0 & $0.0(0.0-209.7)$ & & 3 & $170.5(35.2-498.5)$ & \\
\hline Previously treated TB & & & & 0.015 & & & $<0.001$ \\
\hline No & $6,227.8$ & 2 & $32.1(3.9-115.9)$ & & 13 & $208.7(95.3-322.2)$ & \\
\hline Yes & 155.7 & 1 & $642.3(16.2-3,577.4)$ & & 3 & $1,926.8(397.6-5,632.6)$ & \\
\hline Chronic bronchitis & & & & 0.808 & & & 0.116 \\
\hline No & $6,081.6$ & 3 & $49.3(10.2-144.2)$ & & 14 & $230.2(109.6-350.8)$ & \\
\hline Yes & 286.5 & 0 & $0.0(0.0-1,288.0)$ & & 2 & $698.1(84.5-2,520.1)$ & \\
\hline Pneumoconiosis & & & & 0.960 & & & 0.890 \\
\hline No & $6,366.5$ & 3 & $47.1(9.7-137.8)$ & & 16 & $251.3(128.2-374.5)$ & \\
\hline Yes & 12.8 & 0 & $0.0(0.0-28,828.1)$ & & 0 & $0.0(0.0-28,828.1)$ & \\
\hline $\begin{array}{l}\text { Self-reported cigarette } \\
\text { smoking }\end{array}$ & & & & 0.475 & & & 0.880 \\
\hline Never smoking & $5,206.4$ & 2 & $38.4(4.6-138.7)$ & & 13 & $249.7(114.0-385.4)$ & \\
\hline Ever or current smoking & $1,173.9$ & 1 & $85.2(2.2-474.5)$ & & 3 & $255.6(52.7-747.1)$ & \\
\hline Self-reported drinking & & & & 0.410 & & & 0.374 \\
\hline Never drinking & $5,339.8$ & 2 & $37.5(4.5-135.2)$ & & 12 & $224.7(97.6-351.9)$ & \\
\hline Ever or current drinking & $1,031.6$ & 1 & $96.9(2.5-539.9)$ & & 4 & $387.7(105.7-992.6)$ & \\
\hline BMI level & & & & 0.230 & & & 0.014 \\
\hline$<18.5$ & 295.6 & 0 & $0.0(0.0-1,248.3)$ & & 1 & $338.3(8.6-1,884.3)$ & \\
\hline $18.5-$ & $3,211.8$ & 3 & $93.4(19.3-273.1)$ & & 14 & $435.9(207.6-664.2)$ & \\
\hline $24-$ & $2,189.2$ & 0 & $0.0(0.0-168.6)$ & & 0 & $0.0(0.0-168.6)$ & \\
\hline $28-$ & 683.7 & 0 & $0.0(0.0-539.7)$ & & 1 & $146.3(3.7-814.7)$ & \\
\hline
\end{tabular}

Note: 10 study sites: located in Zhejiang, Jiangsu, Guangdong, Shanghai, Heilongjiang, Henan, Hubei, Sichuan, Guangxi, and Yunnan. Not all total person-year for subgroups were equal because of missing data.

Abbreviations: $\mathrm{DM}=$ diabetes mellitus; $\mathrm{TB}=$ tuberculosis; $\mathrm{BMI}=$ body mass index. 
TABLE 3. Characteristics of TB/DM patients in 10 study sites by different case finding methods, 2013-2015.

\begin{tabular}{|c|c|c|c|c|c|c|c|c|}
\hline \multirow[b]{2}{*}{ Characteristics } & \multicolumn{4}{|c|}{ Bacteriologically positive TB } & \multicolumn{4}{|c|}{ Active TB } \\
\hline & Total $(\%)$ & $\begin{array}{l}\text { Passive case } \\
\text { finding (\%) }\end{array}$ & $\begin{array}{l}\text { Active case } \\
\text { finding }(\%)\end{array}$ & $\boldsymbol{P}$ & Total $(\%)$ & $\begin{array}{c}\text { Passive case } \\
\text { finding (\%) }\end{array}$ & $\begin{array}{l}\text { Active case } \\
\text { finding }(\%)\end{array}$ & $\boldsymbol{P}$ \\
\hline No. of cases & $18(100.0 \%)$ & $7(100.0 \%)$ & $11(100.0 \%)$ & & $44(100.0 \%)$ & $8(100.0 \%)$ & $36(100.0 \%)$ & \\
\hline TB symptoms presence & $9(50.0 \%)$ & $7(100.0 \%)$ & $2(18.2 \%)$ & 0.002 & $31(70.4 \%)$ & $8(100.0 \%)$ & $5(13.9 \%)$ & 0.000 \\
\hline $\begin{array}{l}\text { Involvement of lesion in chest } \\
\text { imagination }\end{array}$ & & & & 0.835 & & & & 0.212 \\
\hline $1-2$ lung fields & $7(38.9 \%)$ & $2(28.6 \%)$ & $5(45.4 \%)$ & & $27(61.4 \%)$ & $3(37.5 \%)$ & $24(66.7 \%)$ & \\
\hline 3-4 lung fields & $5(27.8 \%)$ & $2(28.6 \%)$ & $3(27.3 \%)$ & & $8(18.2 \%)$ & $2(25.0 \%)$ & $6(16.7 \%)$ & \\
\hline $5-6$ lung fields & $6(33.3 \%)$ & $3(42.8 \%)$ & $3(27.3 \%)$ & & $8(18.2 \%)$ & $3(37.5 \%)$ & $5(13.9 \%)$ & \\
\hline Lower lung field involved & $12(66.7 \%)$ & $5(27.8 \%)$ & $7(63.6 \%)$ & 1.000 & $17(38.6 \%)$ & $5(62.5 \%)$ & $12(33.3 \%)$ & 0.125 \\
\hline $\begin{array}{l}\text { Both left and right lungs } \\
\text { involved }\end{array}$ & $10(55.6 \%)$ & $5(27.8 \%)$ & $5(45.4 \%)$ & 0.367 & $17(38.6 \%)$ & $5(62.5 \%)$ & $12(33.3 \%)$ & 0.125 \\
\hline Cavitation presence & $7(38.9 \%)$ & $3(42.8 \%)$ & $4(36.4 \%)$ & 1.000 & $8(18.2 \%)$ & $3(37.5 \%)$ & $5(13.9 \%)$ & 0.117 \\
\hline
\end{tabular}

Note: 10 study sites: located in Zhejiang, Jiangsu, Guangdong, Shanghai, Heilongjiang, Henan, Hubei, Sichuan, Guangxi, and Yunnan.

Abbreviations: $\mathrm{DM}=$ diabetes mellitus; TB=tuberculosis

However, in our study, low prevalence of TB symptoms was identified in all TB patients living with DM, implying that screenings based on symptom enquiry was not enough to find TB cases among DM patients. NPHSP provided a perfect opportunity for conducting active case-finding in DM patients. For known DM patients, quarterly face-to-face interviews by community doctors were required to monitor their DM treatment status. TB suspected symptom screening could be added into this interview, followed by referrals for those displaying $\mathrm{TB}$ symptoms to designated TB hospitals to receive TB-related examinations. For DM patients with risk factors, such as low BMI and previous treatment, periodic CXR examination should be provided for them.

This study had several strengths. First, we designed a population-based cohort study in which the prevalence and incidence rates of TB among DM patients were obtained. Second, TB diagnosis followed the designed procedure strictly. A national expert group reviewed all abnormal chest radiographs and repeated CXR examination and other tests that had been required for bacteriologically-negative $\mathrm{TB}$ to help with the final diagnosis. Third, strict quality control was put in place in the study. On top of internal checks, there was also external monitoring and evaluation.

This study was subject to some limitations. First, the population size was small. Although a high prevalence and incidence rates of TB were observed, a small number of TB cases were found among DM patients, and a large confidence interval was obtained. Second, all screened participants were known DM patients, most of which come from NPHSP records, and about
$5 \%$ were self-reported. The accuracy of DM information mainly relies on the quality of NPHSP records and DM awareness of participants. In addition, we did not take blood glucose measurements, therefore, some real DM patients without confirmed diagnosis in study sites were likely excluded from our screening, and we could not analyze the risk of glucose levels for TB. Finally, information was reported by participants, and there could be incomplete or inaccurate reporting on influencing factors and $\mathrm{TB}$ symptoms.

Acknowledgement: The staff in the provincial CDCs, local CDCs, and other related health care workers in 10 PLADs.

Funding: Supported by the National Twelfth FiveYear Mega-Scientific Projects of Infectious Diseases in China (Grant Number 2013ZX10003-004-001).

doi: $10.46234 / \mathrm{ccdcw} 2022.004$

\# Corresponding author: Hui Zhang, zhanghui@chinacdc.cn.

\footnotetext{
${ }^{1}$ National Center for Tuberculosis Control and Prevention, China CDC, Beijing, China; ${ }^{2}$ Heilongjiang Provincial Center for Disease Control and Prevention, Harbin, Heilongjiang, China; ${ }^{3}$ Minhang District Center for Disease Control and Prevention, Shanghai, China; ${ }^{4}$ Center for Disease Control and Prevention of Danyang County, Danyang, Jiangsu, China; ${ }^{5}$ Center for Disease Control and Prevention of Jiangshan city, Jiangshan, Zhejiang, China; ${ }^{6}$ Henan Provincial Center for Disease control and prevention, Zhengzhou, Henan, China; ${ }^{7}$ Hubei Provincial Center for Disease Control and Prevention, Wuhan, Hubei, China; ${ }^{8}$ Center for Tuberculosis Control of Guangdong Province, Guangzhou, Guangdong, China; ${ }^{9}$ Guangxi Center for Disease Prevention and Control, Nanning, Guangxi Zhuang Autonomous Region, China; ${ }^{10}$ Sichuan Provincial Center for Disease Control and Prevention, Chengdu, Sichuan, China; ${ }^{11}$ Yunnan Provincial Center for Disease Control and Prevention, Kunming, Yunnan, China.
}

Submitted: June 28, 2021; Accepted: November 18, 2021 


\section{REFERENCES}

1. Jeon CY, Murray MB. Diabetes mellitus increases the risk of active tuberculosis: a systematic review of 13 observational studies. PLoS Med 2008;5(7):e152. http://dx.doi.org/10.1371/journal.pmed.0050152.

2. Wang LM, Gao P, Zhang M, Huang ZJ, Zhang DD, Deng Q, et al. Prevalence and ethnic pattern of diabetes and prediabetes in China in 2013. JAMA 2017;317(24):2515 - 23. http://dx.doi.org/10.1001/jama. 2017.7596.

3. Wild S, Roglic G, Green A, Sicree R, King H. Global prevalence of diabetes: estimates for the year 2000 and projections for 2030. Diabetes Care 2004;27(5):1047 - 53. http://dx.doi.org/10.2337/diacare.27.5. 1047.

4. Zhang CY, Zhao F, Xia YY, Yu YL, Shen X, Lu W, et al. Prevalence and risk factors of active pulmonary tuberculosis among elderly people in China: a population based cross-sectional study. Infect Dis Poverty 2019;8(1):7. http://dx.doi.org/10.1186/s40249-019-0515-y.

5. Cheng J, Sun YN, Zhang CY, Yu YL, Tang LH, Peng H, et al. Incidence and risk factors of tuberculosis among the elderly population in China: a prospective cohort study. Infect Dis Poverty 2020;9(1):13. http://dx.doi.org/10.1186/s40249-019-0614-9.

6. Li YY, Guo JT, Xia T, Wu F, Tian JY, Cheng MN, et al. Incidence of pulmonary tuberculosis in Chinese adults with type 2 diabetes: a retrospective cohort study in Shanghai. Sci Rep 2020;10(1):8578. http:// dx.doi.org/10.1038/s41598-020-65603-y.

7. Yang BR, Kang YA, Heo EY, Koo BK, Choi NK, Hwang SS, et al. Regional differences in the incidence of tuberculosis among patients with newly diagnosed diabetes mellitus. Clin Respir J 2018;12(4): 1732 - 8. http://dx.doi.org/10.1111/crj.12737.

8. McAllister SM, Koesoemadinata RC, Santoso P, Soetedjo NNM, Kamil A, Permana $\mathrm{H}$, et al. High tuberculosis incidence among people living with diabetes in Indonesia. Trans R Soc Trop Med Hyg 2020;114 (2):79 - 85. http://dx.doi.org/10.1093/trstmh/trz100.

9. Wood R, Lawn SD, Caldwell J, Kaplan R, Middelkoop K, Bekker LG. Burden of new and recurrent tuberculosis in a major South African city stratified by age and HIV-status. PLoS One 2011;6(10):e25098. http:// dx.doi.org/10.1371/journal.pone.0025098.

10. Lin Y, Li L, Mi FL, Du J, Dong YQ, Li ZL, et al. Screening patients with diabetes mellitus for tuberculosis in China. Trop Med Int Health 2012;17(10):1302 - 8 . http://dx.doi.org/10.1111/j.1365-3156.2012. 03069.x. 